\title{
Cause Traced to User
}

National Cancer Institute

\section{Source}

National Cancer Institute. Cause Traced to User. NCI Thesaurus. Code C91874.

The adverse event was caused partially or wholly by the user of the device including sample handling. 